\title{
Pesticide resistance in intensive agricultural fields: a global issue
}

\section{Leonardo Bianco de Carvalho ${ }^{1 *}$, Liese de Vargas Pereira ${ }^{2}$ and Micheli Fochesato Michelon ${ }^{1}$}

Pesticide resistance is a genetically based phenomenon and occurs when a pesticide is used on a population containing some individuals that are genetically predisposed to be resistant to that pesticide (BELLINGER 1996). Therefore, resistant individuals probably exist in any natural pest population and the misuse of pesticides tends to select the resistant pests over time. Repeated applications and higher treatment rates will kill increasing numbers of the pest but resistant survivors will pass on the resistance genes to the next generation (BELLINGER 1996). The pesticide selection also occurs at low treatment rates with a relative greater importance on standing genetic variation versus novel mutations on a relatively limited number of individuals and highly resistant individuals are very rare (BISI et al. 2013). In any case, the pest resistance evolution is becoming a global issue on agricultural fields where pesticides have been frequently used in the past 30 years.

Resistance may be defined as a heritable change in the sensitivity of a pest population that is reflected in the repeated failure of a product to achieve the expected level of control when used according to the manufacturer's recommendation for that pest species (IRAC 2015). Natural selection by a pesticide allows some initially very rare, naturally occurring, pre-adapted pests with resistance genes to survive and pass the resistance trait on to their offspring (FRAC 2015, HRAC 2015, IRAC 2015). Through continued application of the pesticide with the same action mechanism, selection for the resistant individuals continues so the proportion of resistant pests in the population increases, while susceptible individuals are eliminated by the pesticide; so that, under permanent selection pressure, resistant pests outnumber susceptible ones and the pesticide is no longer effective (IRAC 2015). In addition, the speed with which resistance develops depends on several factors, including how fast pest reproduction occurs, the capacity of adaptation and survival in the environment, the availability of nearby susceptible populations, the persistence and specificity of the pesticide, and the rate, timing, and number of applications made (FRAC 2015, HRAC 2015, IRAC 2015).

The most common pesticide resistances in agricultural fields refer to the resistance of fungi to fungicides, the resistance of insects to insecticides, and the resistance of weeds to herbicides; in spite of the resistance of other pests that can occur, as nematodes, bacteria, mites, and so on). The resistance of fungi, insects, and weeds have been exponentially increasing in the past years around the world (FRAC 2015, HRAC 2015, IRAC 2015), becoming a very important issue in intensive agricultural fields, and mainly in large-scale fields where growers, in almost all cases, depend exclusively on the pesticides to control these organisms.

The prevention of the pesticide resistance is currently an obligation for food production worldwide and it has to be based on the reduction of the pressure of selection on a specific pest by the decreasing of both the frequency of using pesticides of the same action mechanism and the frequency of using only pesticides to control the pests. In this way, integrated pest management plays a very important role as a high-effective pest control as well as being the key for the pest resistance prevention. Thus, we obviously must to find management alternatives, in addition to the chemical control, otherwise the agriculture will pass through difficult days in the near future with regards to pest control.

\footnotetext{
${ }^{1}$ Santa Catarina State University, Lages, SC, Brazil.

${ }^{2}$ Secretaria Estadual da Agricultura, Pecuária e Irrigação do Rio Grande do Sul, Porto Alegre, RS, Brazil.

*Author for correspondence: leonardo.carvalho@udesc.br.
} 


\section{REFERENCES}

BISI R et al. 2013. Evolved polygenic herbicide resistance in Lolium rigidum by low-dose herbicide selection within standing genetic variation. Evolutionary Applications 6: 231-242.

BELLINGER RG. 1996. Pest resistance to pesticides. Clemson University: South Carolina.

FRAC - FUNGICIDE RESISTANCE ACTION COMMITTEE. 2015. Resistance overview. Available at: $<$ http://www.frac.info/resistance-overview $>$. Accessed on: Oct. 17, 2015.

IRAC - INSECTICIDE RESISTANCE ACTION COMMITTEE. 2015. About. Resistance. Available at: $<$ http://www.irac-online.org/about/resistance $>$. Accessed on: Oct. 17, 2015.

HRAC - HERBICIDE RESISTANCE ACTION COMMITTEE. 2015. Overview. Management of resistance. Available at: <http://hracglobal.com/pages/ managementofresistance.asp $\mathrm{x}>$. Accessed on: Oct. 17, 2015. 